\title{
Higher Prevalence of Hypertension among Individuals with Restless Legs Syndrome: A Meta-Analysis
}

\author{
In Cheol Hwang ${ }^{1}$, Kyoung-Sae $\mathrm{Na}^{2}$, Yu Jin Lee ${ }^{3}$, and Seung-Gul Kang ${ }^{2}{ }^{\bowtie}$ \\ ${ }^{1}$ Department of Family Medicine, Gil Medical Center, Gachon University College of Medicine, Incheon, Republic of Korea \\ ${ }^{2}$ Department of Psychiatry, Gil Medical Center, Gachon University College of Medicine, Incheon, Republic of Korea \\ ${ }^{3}$ Department of Psychiatry and Center for Sleep and Chronobiology, Seoul National University College of Medicine and Hospital, \\ Seoul, Republic of Korea
}

Objective This study investigated the proposed association between restless legs syndrome (RLS) and the prevalence of hypertension. Methods A meta-analysis was conducted based on searches of the PUBMED, EMBASE, Cochrane Library, and Korean electronic databases. Cohort and cross-sectional studies reporting the incidence of hypertension in individuals with RLS were included. Dichotomous data were pooled to obtain an odds ratio (OR) and 95\% confidence interval (CI) for the prevalence of hypertension in individuals with RLS. The main outcome measure of the study was prevalence of hypertension in patients with RLS compared with a control group.

Results One cohort study and eight cross-sectional studies were included in the meta-analysis. Individuals with RLS had an increased prevalence of hypertension (all studies: $\mathrm{OR}=1.13,95 \% \mathrm{CI}=1.04-1.23$; cross-sectional studies: $\mathrm{OR}=1.12,95 \% \mathrm{CI}=1.01-1.24$ ). However, in subgroup analyses controlling for cardiovascular risk factors, such as diabetes mellitus and dyslipidemia, the differences in the prevalence of hypertension between RLS and control patients were no longer significant.

Conclusion Patients with RLS may have a higher prevalence of hypertension, according to a pooled analysis, but the results remain to be confirmed in well-designed prospective studies. Psychiatry Investig 2018;15(7):701-709

Key Words Restless legs syndrome, Hypertension, Prevalence, Meta-analysis.

\section{INTRODUCTION}

Restless legs syndrome (RLS) is a sleep and sensorimotor disorder, the prevalence of which varies depending on the population analyzed and methods applied. However, it is generally estimated that $5-10 \%$ of the adult population suffers from RLS worldwide. ${ }^{1,2}$ Typical clinical manifestations of RLS include uncomfortable sensations in, and irresistible urges to move, the legs. These symptoms are either aggravated or start at night, and are temporarily relieved by leg movements. RLS is a chronic and distressing disorder that frequently causes insomnia, impairs sleep quality and quality of

Received: October 20, 2017 Revised: January 14, 2018

Accepted: February 26, 2018

$\bowtie$ Correspondence: Seung-Gul Kang, MD, PhD

Department of Psychiatry, Gil Medical Center, Gachon University College of Medicine, 21 Namdong-daero 774beon-gil, Namdong-gu, Incheon 21565, Republic of Korea

Tel: +82-32-468-9932, Fax: +82-32-468-9962, E-mail: kangsg@gachon.ac.kr

(a) This is an Open Access article distributed under the terms of the Creative Commons Attribution Non-Commercial License (http://creativecommons.org/licenses/bync/4.0) which permits unrestricted non-commercial use, distribution, and reproduction in any medium, provided the original work is properly cited. life, and carries psychological consequences. ${ }^{3,4}$ In addition, RLS has been suggested to be associated with various comorbidities, especially cardiovascular disease (CVD) and related conditions. $^{5}$

CVD as a comorbidity in patients with RLS has been determined in many cross-sectional studies with large sample sizes, ${ }^{6-8}$ although the findings of prospective studies have been inconsistent. ${ }^{9,10}$ The potential underlying mechanism of an increased risk of CVD in RLS is not clear, but may involve hypertension, as periodic limb movements during sleep (PLMS) were shown to be related to blood pressure increases. ${ }^{11,12}$ Alternatively, a blunted nocturnal blood pressure dipping response due to RLS- and PLMS-related insomnia may cause hypertension and CVD. ${ }^{13}$ Observational studies have also reported a relationship between RLS or PLMS and high nocturnal blood pressure, ${ }^{14}$ as well as daytime hypertension. $^{15}$

Most epidemiologic studies of the incidence of hypertension in RLS were cross-sectional in design, ${ }^{6,7,16-24}$ although a few cohort studies ${ }^{25}$ have also been published. The prevalence of hypertension in RLS was high in some studies, ${ }^{16,17,23,25}$ 
whereas the results were contradictory in others. ${ }^{6,7,18-22,24}$ Therefore, the present work consisted of a comprehensive meta-analysis of the prevalence of hypertension in RLS versus non-RLS patients, and examined the potential reasons for the previous inconsistent findings in sub-group analyses.

\section{METHODS}

\section{Information sources and search strategy}

The PUBMED, EMBASE, and Cochrane Library databases were searched comprehensively from their inception until October 28, 2016. No language restrictions were applied. The Korean electronic databases (Korean Studies Information Service System, the National Assembly Library, DBpia, and RISS4U) were searched for the same period. All searches were conducted as suggested by the Meta-analysis of Observational Studies in Epidemiology ${ }^{26}$ Ethical approval was not required for this analysis because the data used in this study were extracted from the published literature.

\section{Study selection and eligibility criteria}

The search terms were related to RLS ('restless legs syndrome' or 'RLS' or 'Ekbom syndrome'), hypertension ('hyperten*' or 'high blood pressure'), and outcomes ('risk' or 'incidence' or 'ratio'). In PUBMED, the key words were ((“"risk" [MeSH Terms] OR "risk"[All Fields]) OR ("epidemiology" [Subheading] OR "epidemiology" [All Fields] OR "incidence" [All Fields] OR "incidence" [MeSH Terms]) OR ("Ratio (Oxf)" [Journal] OR "ratio" [All Fields])) AND ("restless legs syndrome" [All Fields] OR RLS[All Fields] OR "Ekbom syndrome" [All Fields])) AND ((hyperten*[All Fields] OR "high blood pressure"[All Fields]). In EMBASE, the key words were ('risk'/exp OR risk OR 'incidence'/exp OR incidence OR; 'ratio'/exp OR ratio) AND ('restless legs syndrome'/exp OR 'restless legs syndrome' OR rls OR 'ekbom syndrome'/exp OR 'ekbom syndrome') AND (hyperten* OR 'high blood pressure'/exp OR 'high blood pressure'). The reference lists of relevant articles were reviewed to identify additional papers not identified in the database searches. Case reports, reviews, and non-peerreviewed sources (e.g., conference abstracts, author replies) were excluded. Original observational studies of the association between RLS and hypertension prevalence in humans were included, as were studies in which the data were evaluated using the International Restless Legs Syndrome Study Group (IRLSSG) diagnostic criteria. ${ }^{27}$ Studies that used different RLS diagnostic criteria or enrolled only individuals with frequent RLS symptoms were excluded, as were publications in which hypertension was a risk factor and blood pressure was a continuous variable..$^{25}$
Both a measure of association [odds ratio (OR) and hazard ratio (HR)] and a measure of precision [confidence interval (CI)] for the association between RLS and hypertension prevalence were obtained from the studies, together with the fully adjusted and unadjusted measures of association. We assumed that the HR was close to the OR because the incidence of RLS was sufficiently low for the rare disease assumption to apply. ${ }^{28}$ In cases of multiple publications based on the same study sample, the most recent publication was reviewed.

\section{Data extraction}

All relevant articles were independently evaluated by two of the authors (IC Hwang and SG Kang), and disagreements were resolved by consensus or consultation with the third author (KS Na). The following data were selected from each study: first author, year of publication, country in which the study was performed, population and setting of the study, number of participants, study design, criteria and method for diagnosis of RLS and hypertension, OR (or HR) and 95\% $\mathrm{CI}$, and the confounding (and subsequently adjusted) variables. We evaluated the methodological quality of the studies using the Newcastle-Ottawa scale by means of two investigators, independently, ${ }^{29}$ and any discrepancies were resolved by consensus.

\section{Statistical analysis}

The relationship between RLS and the prevalence of hypertension was investigated in a meta-analysis followed by a sub-group meta-analysis that took account of the following factors: study design (cross-sectional), sex, method of RLS evaluation (self-reported questionnaire vs. face-to-face interview), adjustment for potential confounders [diabetes mellitus (DM), dyslipidemia, established CVD, body mass index, and smoking status].

A meta-regression analysis was conducted to identify the effects of covariates, including DM, dyslipidemia, CVD, $\mathrm{BMI}$, and smoking on the study results.

A pooled OR with a $95 \% \mathrm{CI}$ was calculated based on data extracted from individual studies. To calculate the variance in the log OR from each study, the $95 \%$ CI was converted to natural $\log$ values by taking the span of the $\mathrm{CI}$ and dividing it by 3.92. Summary OR estimates were derived using the method of DerSimonian and Laird. ${ }^{30}$

To test for the proportion of variation, Higgins' $I^{2}$, which indicates the variation (\%) across studies, was used. In our analyses, the DerSimonian and Laird random effects model, which is the generally accepted approach, was applied. A potential small-study effect and publication bias were assessed using Egger's test and visual inspection of funnel plot. All 
statistical analyses were performed with Comprehensive Meta-Analysis software (ver. 3; Biostat, Englewood, NJ, USA).

\section{RESULTS}

\section{Study selection and characteristics}

A flow diagram for the identification of suitable studies (according to PRISMA) is shown in Figure 1. Through a systematic search of the electronic database, and a manual search for articles cited in the retrieved studies, 451 articles were obtained in total. Nine studies (429,617 participants) were included in our final meta-analysis after the review process shown in Figure 1.

Eight of the nine studies were cross-sectional ${ }^{16-22,24}$ and one was a cohort study. ${ }^{25}$ The most important characteristics of the studies are summarized in Table 1. We also showed the quality of all enrolled studies in the meta-analysis in Supplementary Table 1 after assessment by the Newcastle-Ottawa scale. Most of the studies $(n=7)$ were conducted in the USA $^{21,22,25}$ or in European countries; ${ }^{18-20,24}$ one study was performed in Taiwan ${ }^{17}$ and another in Mexico. ${ }^{16}$ Adjustment was made for age in all of the studies. Sex was adjusted for in four studies; in the other five studies, only males $(n=2)$ or fe- males $(n=3)$ were enrolled. Adjustments for other confounders varied according to the nature of the study.

\section{Meta-analysis}

Individuals with RLS were associated with a higher prevalence of hypertension ( $\mathrm{OR}=1.13,95 \% \mathrm{CI}=1.04-1.23$, $\mathrm{p}=0.003)$, as shown in Figure 2 and Table 2. In cross-sectional studies, the prevalence of hypertension in RLS patients was significantly higher $(\mathrm{OR}=1.12,95 \% \mathrm{CI}=1.01-1.24, \mathrm{p}=0.028)$.

As shown in Figure 3, visual inspection of the funnel plot and the application of pseudo-95\% confidence limits and Egger's bias ( $\mathrm{t}=0.61,95 \% \mathrm{CI}=-1.70-2.87, \mathrm{p}=0.562)$ did not suggest publication bias.

\section{Sub-group analyses}

In the sub-group analyses by the RLS evaluation method, higher prevalence of hypertension in RLS patients was determined only in studies using self-reported questionnaires ( $\mathrm{OR}=1.13,95 \% \mathrm{CI}=1.01-1.27, \mathrm{p}=0.036)$, and not in those employing face-to-face interviews $(\mathrm{OR}=1.08,95 \% \mathrm{CI}=0.80$ $1.45, \mathrm{p}=0.615)$

There was a higher prevalence of hypertension in RLS patients in unadjusted studies for $\mathrm{DM}(\mathrm{OR}=1.25,95 \% \mathrm{CI}=1.00-$

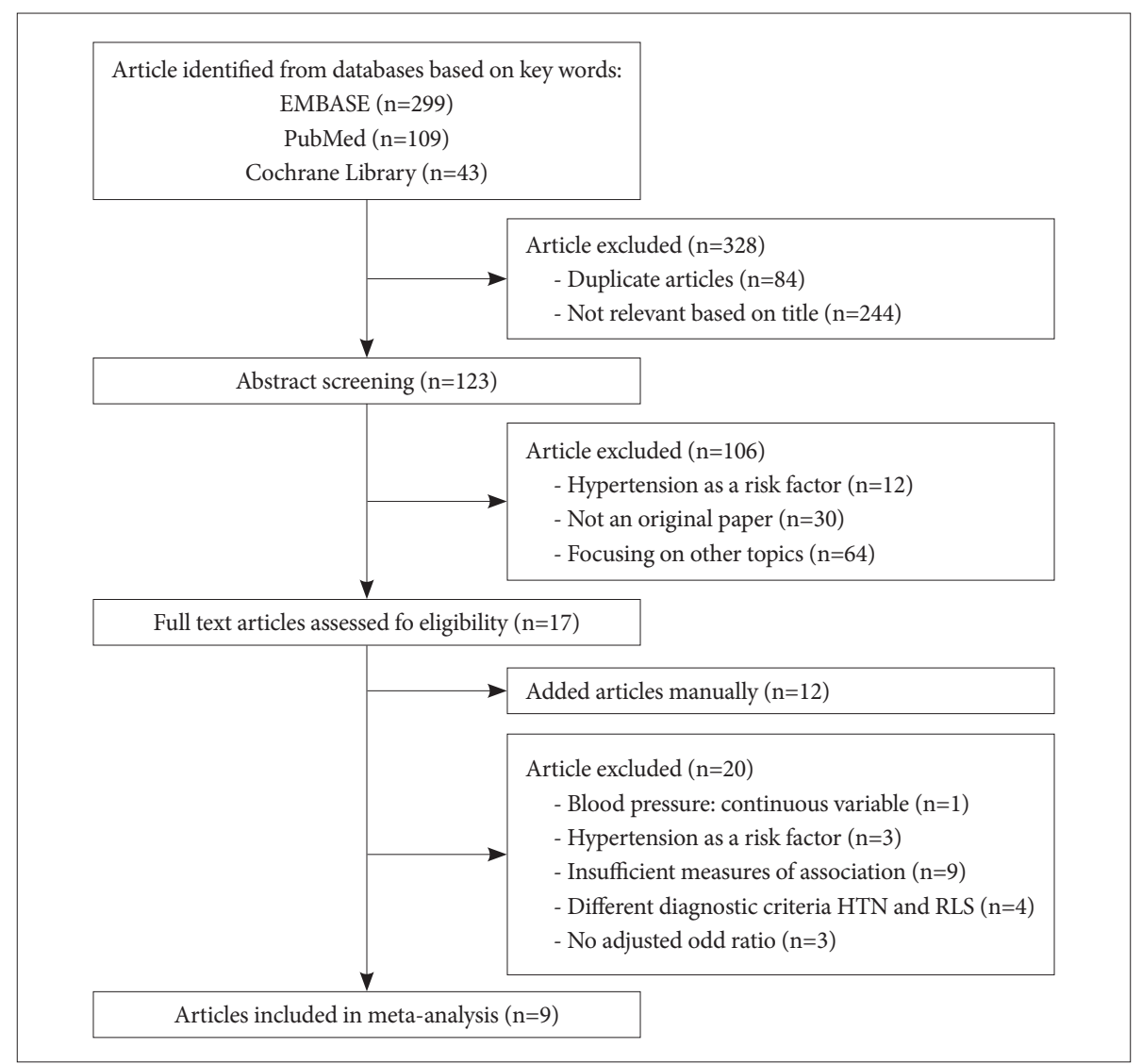

Figure 1. Flow chart for identifying articles eligible for inclusion in our meta-analysis. HTN: hypertension, RLS: restless legs syndrome. 


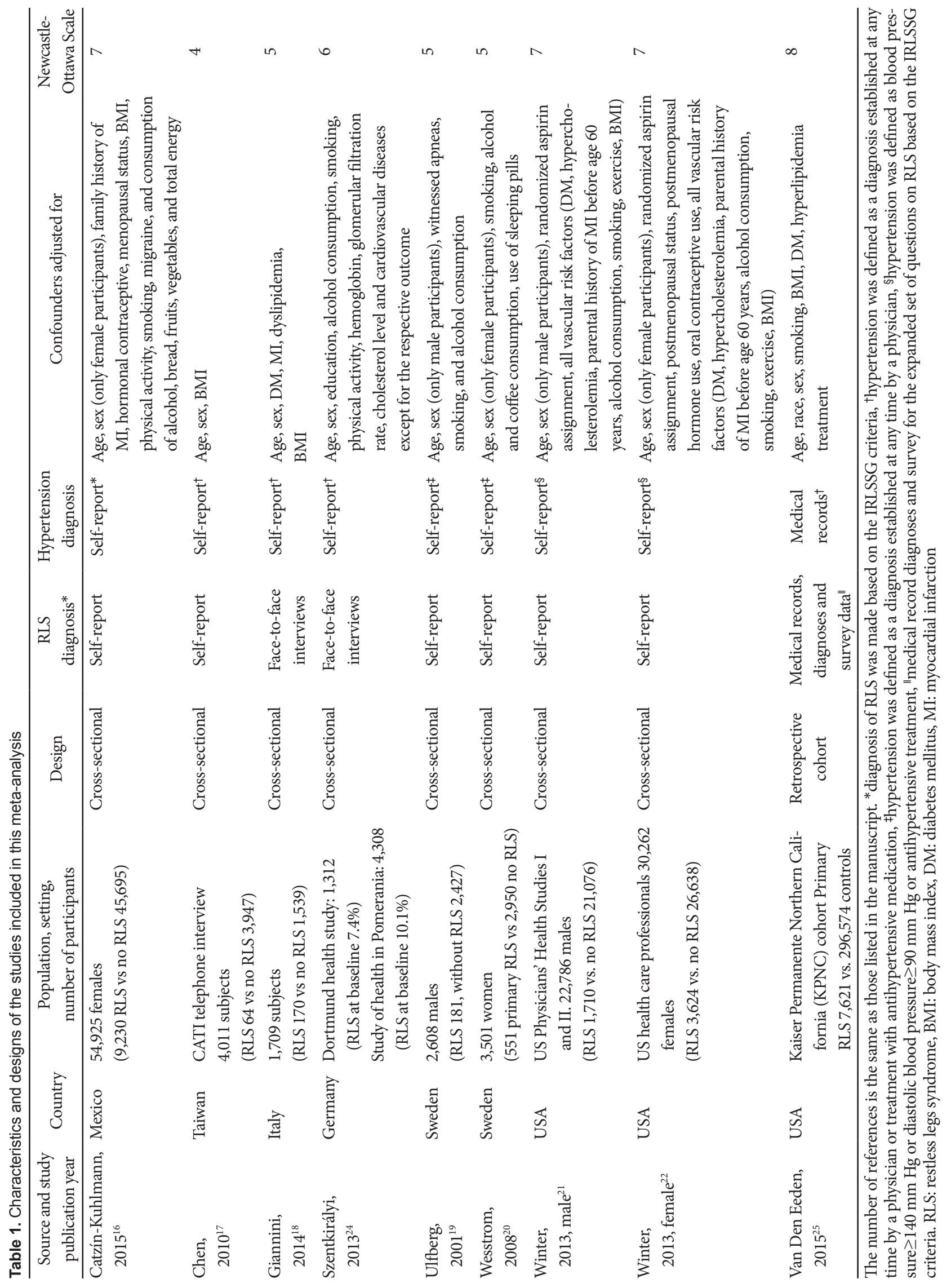




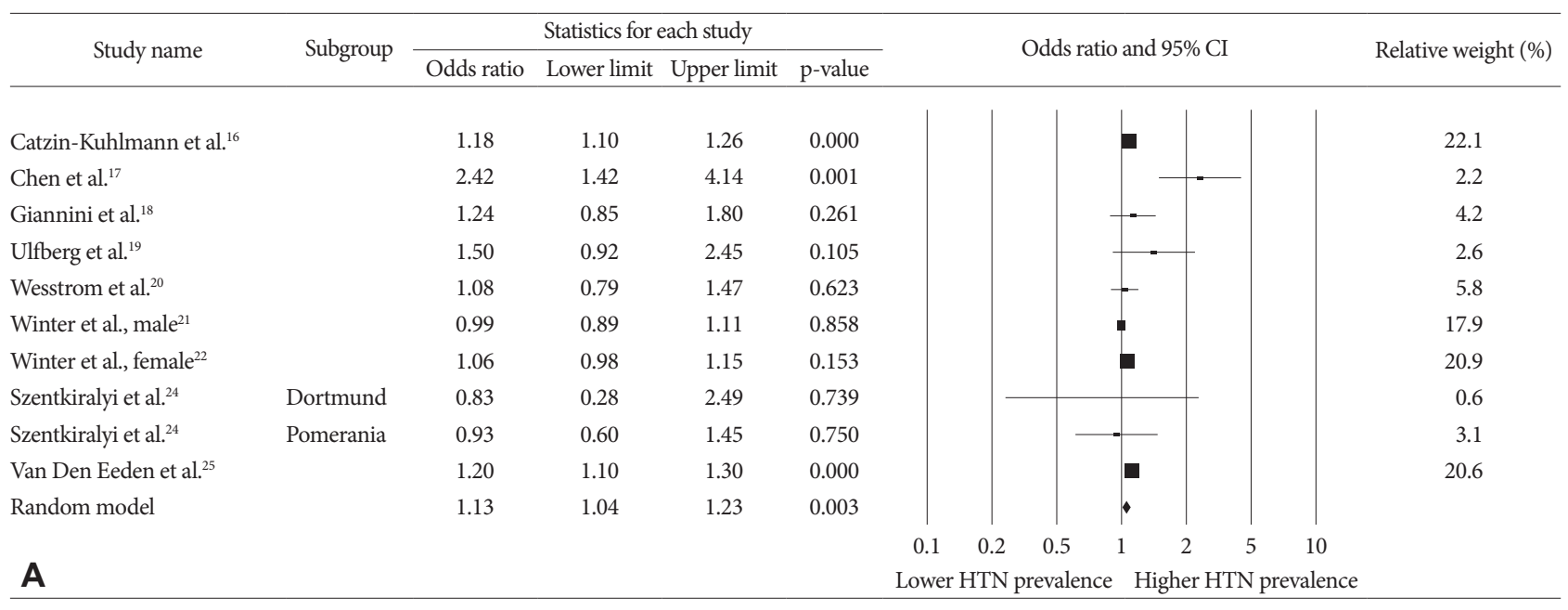

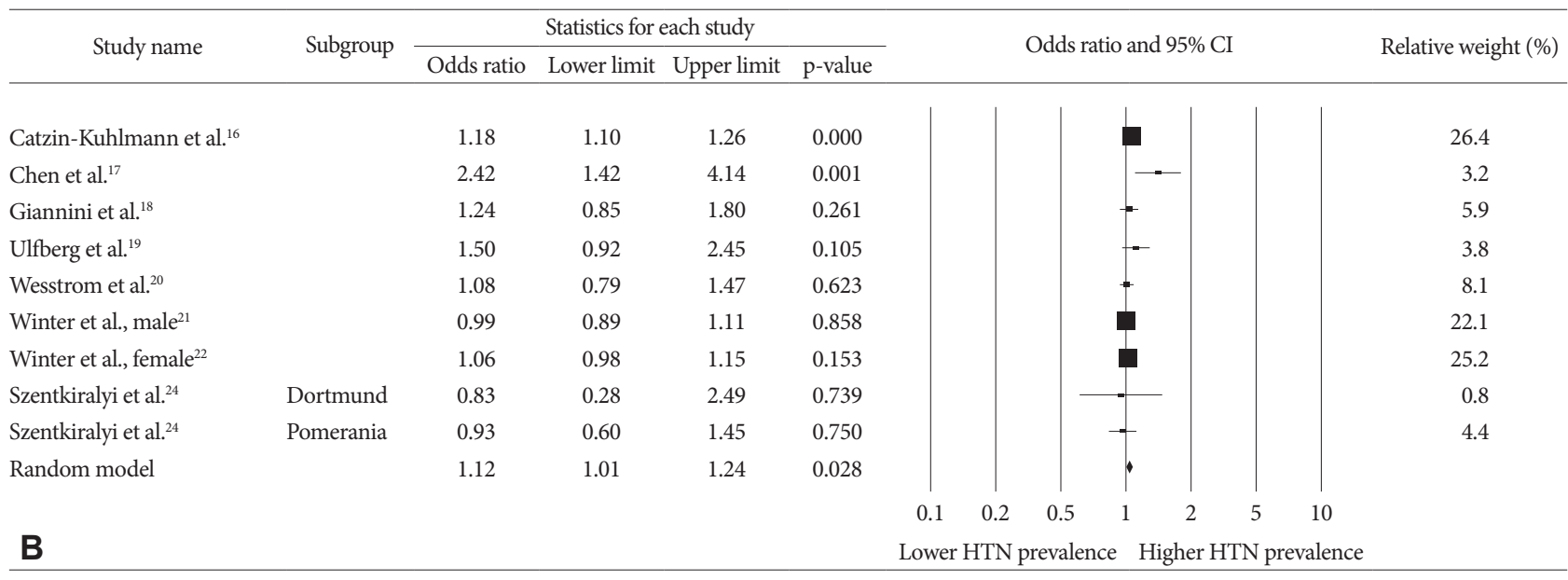

Figure 2. Forest plot showing the effect of RLS on the prevalence of hypertension for the studies included in the meta-analysis. A: All studies. B: Cross-sectional studies. Cl: confidence interval.

1.55, $\mathrm{p}=0.049)$, dyslipidemia (OR=1.33, 95\% $\mathrm{CI}=1.04-1.72$, $\mathrm{p}=0.026)$, and established CVD (OR=1.14, 95\% CI $=1.04-1.25$, $\mathrm{p}=0.005$ ). However, the relationships between the prevalence of hypertension and RLS were not significant in studies adjusted for the same confounders. In terms of smoking status, a higher prevalence of hypertension was observed in RLS patients only in studies adjusted for smoking status $(\mathrm{OR}=1.11$, 95\% CI=1.03-1.20, $\mathrm{p}=0.005$ ); no higher prevalence of hypertension was observed in RLS patients in studies that were not adjusted for smoking status.

While a significant relationship between RLS and hypertension was found in studies that enrolled only females (OR=1.12, 95\% CI=1.03-1.22, $\mathrm{p}=0.011)$, this was not the case in those that enrolled only males (OR=1.13, 95\% CI $=0.77-$ $1.66, \mathrm{p}=0.518)$.

In the meta-regression analysis to investigate the impact of the covariates on the study results, smoking had a significant impact on the study results (Table 3).

\section{DISCUSSION}

The results of our meta-analysis indicate a higher prevalence of hypertension in individuals with RLS, although the results were only marginally significant. The importance of our study is that it examined the inconsistent findings of previous studies and allowed us to conclude that RLS, which is a common condition, not only causes distress but is also associated with a higher prevalence of hypertension, one of the most significant risk factors for CVD. However, strong support for this result could not be obtained because of the small number of prospective studies included, and because the relationship between RLS and hypertension was no longer significant after adjusting for the confounders of metabolic syndrome, such as DM and dyslipidemia.

Although the physiological mechanism underlying the association between RLS and hypertension is not clear, putative mechanisms suggested by previous studies include: 1) $80 \%$ of 
Table 2. Hypertension risk among restless legs syndrome (RLS) patients by study design and confounders

\begin{tabular}{|c|c|c|c|c|c|}
\hline Analyses & No. of studies & Summary OR (95\% CI) & $\mathrm{p}$ value & Proportion of variation, $\mathrm{I}^{2}$ & Model \\
\hline Overall & 9 & $1.13(1.04-1.23)^{\dagger}$ & $0.003^{\dagger}$ & $58.9 \%$ & Random-effects \\
\hline \multicolumn{6}{|l|}{ Study design } \\
\hline Cross-sectional ${ }^{16-22,24}$ & 8 & $1.12(1.01-1.24)^{\dagger}$ & $0.028^{\dagger}$ & $58.6 \%$ & Random-effects \\
\hline Cohort $^{25}$ & 1 & $1.2^{*}(1.10-1.30)^{\dagger}$ & & & \\
\hline \multicolumn{6}{|l|}{ Limited to } \\
\hline Male $^{19,21}$ & 2 & $1.13(0.77-1.66)$ & 0.518 & $61.9 \%$ & Random-effects \\
\hline Female $^{16,20,22}$ & 3 & $1.12(1.03-1.22)^{\dagger}$ & $0.011^{\dagger}$ & $51.1 \%$ & Random-effects \\
\hline \multicolumn{6}{|l|}{ RLS diagnosis by } \\
\hline Self-report ${ }^{16,17,19-22}$ & 6 & $1.13(1.01-1.27)^{\dagger}$ & $0.036^{\dagger}$ & $72.4 \%$ & Random-effects \\
\hline Face to face interview ${ }^{18,24}$ & 2 & $1.08(0.80-1.45)$ & 0.615 & $0 \%$ & Random-effects \\
\hline \multicolumn{6}{|l|}{ Potential confounders } \\
\hline \multicolumn{6}{|l|}{$\mathrm{DM}$} \\
\hline Unadjusted $^{16,17,19,20,24}$ & 5 & $1.25(1.00-1.55)^{\dagger}$ & $0.049^{\dagger}$ & $58.2 \%$ & Random-effects \\
\hline Adjusted $^{18,21,22,25}$ & 4 & $1.10(0.99-1.21)$ & 0.077 & $66.2 \%$ & Random-effects \\
\hline \multicolumn{6}{|l|}{ Dyslipidemia } \\
\hline Unadjusted $d^{16,17,19,20}$ & 4 & $1.33(1.04-1.72)^{\dagger}$ & $0.026^{\dagger}$ & $62.6 \%$ & Random-effects \\
\hline Adjusted $^{18,21,22,24,25}$ & 5 & $1.08(0.99-1.19)$ & 0.092 & $58.3 \%$ & Random-effects \\
\hline \multicolumn{6}{|l|}{ Established CVD } \\
\hline Unadjusted $^{16,17,19-22,25}$ & 7 & $1.14(1.04-1.25)^{\dagger}$ & $0.005^{\dagger}$ & $70.9 \%$ & Random-effects \\
\hline Adjusted $^{18,24}$ & 2 & $1.08(0.80-1.45)$ & 0.615 & $0 \%$ & Random-effects \\
\hline \multicolumn{6}{|l|}{ BMI } \\
\hline Unadjusted $^{19,20,24}$ & 3 & $1.10(0.87-1.40)$ & 0.4 & $0 \%$ & Random-effects \\
\hline Adjusted $^{16-18,21,22,25}$ & 6 & $1.14(1.04-1.26)^{\dagger}$ & $0.007^{\dagger}$ & $74.4 \%$ & Random-effects \\
\hline \multicolumn{6}{|l|}{ Smoking status } \\
\hline Unadjusted $^{17,18}$ & 2 & $1.68(0.88-3.23)$ & 0.118 & $75.1 \%$ & Random-effects \\
\hline Adjusted $^{16,19-22,24,25}$ & 7 & $1.11(1.03-1.20)^{\dagger}$ & $0.005^{\dagger}$ & $56.6 \%$ & Random-effects \\
\hline
\end{tabular}

The numbers of references are same to those of the reference list in the manuscript. *hazard ratio, ${ }^{\dagger}$ statistically significant results. OR: odds ratio, CI: confidence interval, DM: diabetes mellitus, CVD: cardiovascular disease, BMI: body mass index

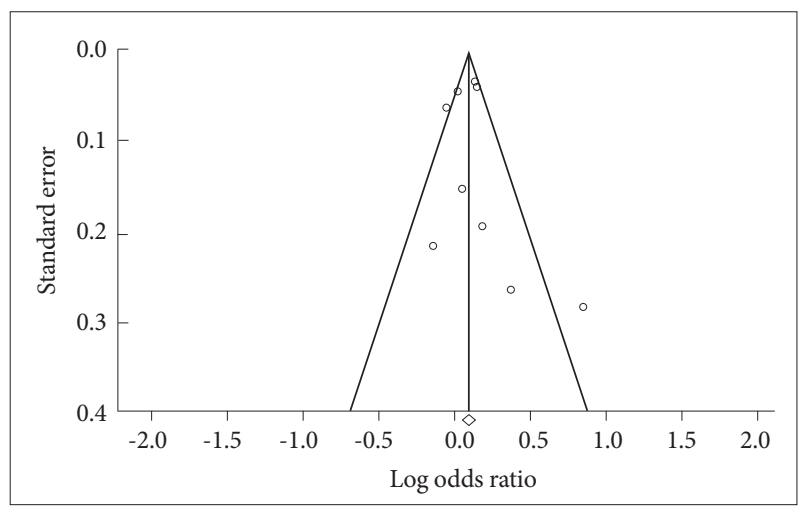

Figure 3. Funnel plot of the nine included studies. The effect size is shown on the $x$-axis and the standard error on the $y$-axis.

RLS patients have PLMS, a condition that, during sleep, increases heart rate and blood pressure, both of which are risk factors for hypertension. ${ }^{31-33}$ 2) RLS symptoms cause distress and sleep impairment, and therefore stress, which can activate the autonomic nervous system, induce arterial baroreflex dysfunction, and increase the synthesis of catecholamines. ${ }^{14,34,35} 3$ ) The activation by RLS of the hypothalamicpituitary-adrenal axis is related to increased nocturnal cortisol and blood pressure levels. ${ }^{36}$

Since most of the studies included in our meta-analysis were cross-sectional in design, the nature of the association between RLS and hypertension could not be established. The cohort study performed in the USA found an increased risk of hypertension in RLS patients. ${ }^{25}$ Thus, well-designed prospective cohort studies are needed to examine the risk of hypertension in RLS. To be conclusive, these studies should include only patients with idiopathic RLS and exclude all those with secondary RLS, including RLS due to DM neuropathy and renal failure, both of which are risk factors for hypertension. We should not depend entirely on IRLSSG criteria, 
Table 3. Meta-regression to identify the effects of covariates on the study results

\begin{tabular}{lcccccc}
\hline \multicolumn{1}{c}{ Covariates } & Coefficient & Standard error & $95 \%$ lower & $95 \%$ upper & Z value & p value \\
\hline Intercept & -0.5031 & 0.3625 & -1.2135 & 0.2073 & -1.39 & 0.1651 \\
DM & 0.3039 & 0.6815 & -1.0319 & 1.6397 & 0.45 & 0.6557 \\
Dyslipidemia & -0.2124 & 0.6889 & -1.5626 & 1.1378 & -0.31 & 0.7579 \\
CVD & 0.5772 & 0.3661 & -0.1404 & 1.2947 & 1.58 & 0.1149 \\
BMI & 0.0129 & 0.1694 & -0.3191 & 0.3449 & 0.08 & 0.9391 \\
Smoking & 0.7183 & 0.2975 & 0.1352 & 1.3013 & 2.41 & $0.0158^{*}$ \\
\hline
\end{tabular}

*statistically significant results. DM: diabetes mellitus, CVD: cardiovascular disease, BMI: body mass index

which cannot differentiate between primary and secondary RLS, as secondary RLS, including DM neuropathy, and renal failure, were associated with an increased hypertension risk in a previous cohort study. ${ }^{25}$ Moreover, the association between RLS and hypertension may be in the opposite direction, that is, hypertension could be a risk factor for RLS; vascular changes due to hypertension may induce RLS symptoms and antihypertensive medication may cause side effects that are similar to RLS symptoms. ${ }^{723}$ However, this reversed association was not supported by other studies that used a prospective design. ${ }^{37,38}$

DM, dyslipidemia, and established comorbid CVD may be important pathways linking RLS and hypertension, as they showed a significant association in studies that were unadjusted for these confounders, but not after adjustment. Although there is some debate, a relationship between DM and RLS has been reported by many studies, and DM neuropathy is one of the common causes of secondary RLS. ${ }^{39} \mathrm{DM}$, dyslipidemia, and hypertension are the main components of metabolic syndrome and important risk factors for CVD. Therefore, to investigate the direct relationship between RLS and hypertension, basic research that adjusts for these confounders is needed. Future prospective studies on the association between RLS and hypertension should control for the use of antihypertensive medication, ${ }^{40}$ given that beta-blockers and calcium channel blockers can ameliorate, but also aggravate, RLS symptoms. ${ }^{41}$ Greater attention must be paid to managing the risk factors of metabolic syndrome and adequately treating RLS.

Our study also suggests that certain lifestyle variables (smoking status and obesity) greatly influence the association between RLS and hypertension. Smoking status impacted the study results in the meta-regression analysis. This can, in part, be explained by reverse causation, as patients with hypertension are more likely to adopt healthy behaviors than non-hypertensive controls. ${ }^{42}$

In the sub-group analyses of studies that enrolled only females $^{16,20,22}$ there was a higher prevalence of hypertension in those with RLS, whereas this was not demonstrated in the studies that enrolled only males. ${ }^{19,21}$ The following is proposed: 1) higher susceptibility of females to insomnia and arousal; ${ }^{43}$ 2) higher prevalence of RLS in females; ${ }^{4}$ ) greater variability of PLMS ${ }^{44}$ and the higher amplitude of bradycardia (which follows tachycardia) in females in response to PLMS; ${ }^{45}$ and 4) sex-related differences in sleep-arousal and circadian rhythms in the hypothalamic-pituitary-gonadal and hypothalamic-pituitary-adrenal axes. ${ }^{46}$ However, whether there is a sex difference in the prevalence of hypertension remains unclear, because the number of studies in both sets of analyses was small and the characteristics of the study population varied. In addition, the results of studies conducted only on males show a wide $95 \%$ CI (0.77-1.66), which does not rule out the possibility of a false negative.

The association of hypertension with RLS was significant in the studies based on self-report evaluations of RLS, but not in those in which evaluations were made during face-toface interviews. Self-reporting might be vulnerable to recall bias and misclassification. Also, considering the wide 95\% CI (0.82-1.43) of the studies employing face-to-face interviews, the possibility of type II error due to the small sample size cannot be ruled out.

The limitation in this study was the need to adopt only IRLSSG diagnostic criteria, which are the most commonly used RLS criteria, because we wanted to select studies with similar study designs to ensure homogeneity. Therefore, we could not include studies with different frequency or severity criteria for the RLS diagnosis. Thus, we were unable to investigate the difference in prevalence of hypertension according to the severity and frequency of RLS. One study reported that the higher the frequency of RLS, the higher the risk of hypertension. ${ }^{16}$ Thus, whether these two conditions exhibit an exposure-response relationship merits further research and clinical investigation. The small number of studies also hindered assessment of the prevalence of hypertension in patients with primary versus secondary RLS, although a difference was demonstrated previously. ${ }^{25}$ On the other hand, we used funnel plots and Egger's test to examine publication bias. It is generally recommended to use such methods when 
the number of individual studies is substantially more than 10. ${ }^{47}$ Otherwise, the funnel plot and Egger's test might have low statistical power and ability to detect actual asymmetry in the funnel plot. Hence, the results from the funnel plot and the Egger's test might not have fully distinguished asymmetry in the included studies.

In summary, the results of our pooled analysis suggest that individuals with RLS show a higher prevalence of hypertension, but well-designed, prospective studies are needed to confirm this finding. Future prospective research should differentiate between primary and secondary RLS and quantify the severity and frequency of RLS to investigate the relationship between RLS and hypertension more accurately.

\section{Supplementary Materials}

The online-only Data Supplement is available with this article https://doi.org/10.30773/pi.2018.02.26.

\section{Acknowledgments}

This research was supported by the Basic Science Research Program through the National Research Foundation of Korea (NRF) funded by the Ministry of Education (NRF-2017R1D1A1B03032431).

This research was supported by a grant of the Korea Health Technology R\&D Project through the Korea Health Industry Development Institute (KHIDI), funded by the Ministry of Health \& Welfare, Republic of Korea (grant number : HI17C2665).

\section{REFERENCES}

1. Allen RP, Walters AS, Montplaisir J, Hening W, Myers A, Bell TJ, et al. Restless legs syndrome prevalence and impact: REST general population study. Arch Intern Med 2005;165:1286-1292.

2. Tison F, Crochard A, Leger D, Bouee S, Lainey E, El Hasnaoui A. Epidemiology of restless legs syndrome in French adults: a nationwide survey: the INSTANT Study. Neurology 2005;65:239-246.

3. Sevim S, Dogu O, Kaleagasi H, Aral M, Metin O, Camdeviren H. Correlation of anxiety and depression symptoms in patients with restless legs syndrome: a population based survey. J Neurol Neurosurg Psychiatry 2004;75:226-230.

4. Allen RP, Montplaisir J, Walters AS, Ferini-Strambi L, Högl B. Restless Legs Syndrome and Periodic Limb Movements during Sleep A2 - Kryger, Meir. In: Roth T, Dement WC, Editors. Principles and Practice of Sleep Medicine (Sixth Edition). Philadelphia: Elsevier, 2017, p.923-934. e6.

5. Trenkwalder C, Allen R, Hogl B, Paulus W, Winkelmann J. Restless legs syndrome associated with major diseases: a systematic review and new concept. Neurology 2016;86:1336-1343.

6. Winkelman JW, Finn L, Young T. Prevalence and correlates of restless legs syndrome symptoms in the Wisconsin Sleep Cohort. Sleep Med 2006; 7:545-552.

7. Winkelman JW, Shahar E, Sharief I, Gottlieb DJ. Association of restless legs syndrome and cardiovascular disease in the Sleep Heart Health Study. Neurology 2008;70:35-42.

8. Ferini-Strambi L, Walters AS, Sica D. The relationship among restless legs syndrome (Willis-Ekbom Disease), hypertension, cardiovascular disease, and cerebrovascular disease. J Neurol 2014;261:1051-1068.

9. Li Y, Walters AS, Chiuve SE, Rimm EB, Winkelman JW, Gao X. Prospective study of restless legs syndrome and coronary heart disease among women. Circulation 2012;126:1689-1694.

10. Winter AC, Schürks M, Glynn RJ, Buring JE, Gaziano JM, Berger K, et al. Restless legs syndrome and risk of incident cardiovascular disease in women and men: prospective cohort study. BMJ Open 2012; 2:e000866. 11. Pennestri MH, Montplaisir J, Colombo R, Lavigne G, Lanfranchi PA. Nocturnal blood pressure changes in patients with restless legs syndrome. Neurology 2007;68:1213-1218.

12. Siddiqui F, Strus J, Ming X, Lee IA, Chokroverty S, Walters AS. Rise of blood pressure with periodic limb movements in sleep and wakefulness. Clin Neurophysiol 2007;118:1923-1930.

13. de la Sierra A, Segura J, Gorostidi M, Banegas JR, de la Cruz JJ, Ruilope LM. Diurnal blood pressure variation, risk categories and antihypertensive treatment. Hypertens Res 2010;33:767-771.

14. Erden EC, Erden I, Turker Y, Sivri N, Dikici S, Ozsahin M. Incremental effects of restless legs syndrome on nocturnal blood pressure in hypertensive patients and normotensive individuals. Blood Press Monit 2012;17:231-234.

15. Espinar-Sierra J, Vela-Bueno A, Luque-Otero M. Periodic leg movements in sleep in essential hypertension. Psychiatry Clin Neurosci 1997;51:103-107.

16. Catzín Kuhlmann A, Juárez Armenta A, Ortiz Panozo E, Monge Urrea A, Puchner KP, Cantú Brito C, et al. Restless legs syndrome and hypertension in Mexican women. Mov Disord Clin Pract 2015;2:274-279.

17. Chen NH, Chuang LP, Yang CT, Kushida CA, Hsu SC, Wang PC, et al. The prevalence of restless legs syndrome in Taiwanese adults. Psychiatry Clin Neurosci 2010;64:170-178.

18. Giannini G, Zanigni S, Melotti R, Gogele M, Provini F, Facheris MF, et al. Association between restless legs syndrome and hypertension: a preliminary population-based study in South Tyrol, Italy. Eur J Neurol 2014;21:72-78.

19. Ulfberg J, Nystrom B, Carter N, Edling C. Prevalence of restless legs syndrome among men aged 18 to 64 years: an association with somatic disease and neuropsychiatric symptoms. Mov Disord 2001;16:11591163.

20. Wesstrom J, Nilsson S, Sundstrom-Poromaa I, Ulfberg J. Restless legs syndrome among women: prevalence, co-morbidity and possible relationship to menopause. Climacteric 2008;11:422-428.

21. Winter AC, Berger K, Glynn RJ, Buring JE, Gaziano JM, Schurks M, et al. Vascular risk factors, cardiovascular disease, and restless legs syndrome in men. Am J Med 2013;126:228-235, 235 e221-222.

22. Winter AC, Schurks M, Glynn RJ, Buring JE, Gaziano JM, Berger K, et al. Vascular risk factors, cardiovascular disease, and restless legs syndrome in women. Am J Med 2013;126:220-227, 227 e221-222.

23. Batool-Anwar S, Malhotra A, Forman J, Winkelman J, Li Y, Gao X. Restless legs syndrome and hypertension in middle-aged women. Hypertension 2011;58:791-796.

24. Szentkiralyi A, Volzke H, Hoffmann W, Happe S, Berger K. A time sequence analysis of the relationship between cardiovascular risk factors, vascular diseases and restless legs syndrome in the general population. J Sleep Res 2013;22:434-442.

25. Van Den Eeden SK, Albers KB, Davidson JE, Kushida CA, Leimpeter $\mathrm{AD}$, Nelson LM, et al. Risk of cardiovascular disease associated with a restless legs syndrome diagnosis in a retrospective cohort study from Kaiser Permanente Northern California. Sleep 2015;38:1009-1015.

26. Stroup DF, Berlin JA, Morton SC, Olkin I, Williamson GD, Rennie D, et al. Meta-analysis of observational studies in epidemiology: a proposal for reporting. Meta-analysis of observational studies in epidemiology (MOOSE) group. JAMA 2000;283:2008-2012.

27. Allen RP, Picchietti D, Hening WA, Trenkwalder C, Walters AS, Montplaisi J. Restless legs syndrome: diagnostic criteria, special considerations, and epidemiology. A report from the restless legs syndrome diagnosis and epidemiology workshop at the National Institutes of Health. Sleep Med 2003;4:101-119.

28. Katz KA. The (relative) risks of using odds ratios. Arch Dermatol 2006;142:761-764.

29. Stang A. Critical evaluation of the Newcastle-Ottawa scale for the assessment of the quality of nonrandomized studies in meta-analyses. Eur J Epidemiol 2010;25:603-605. 
30. DerSimonian R, Laird N. Meta-analysis in clinical trials. Control Clin Trials 1986;7:177-188

31. Walters AS, Rye DB. Review of the relationship of restless legs syndrome and periodic limb movements in sleep to hypertension, heart disease, and stroke. Sleep 2009;32:589-597.

32. Pennestri MH, Montplaisir J, Fradette L, Lavigne G, Colombo R, Lanfranchi PA. Blood pressure changes associated with periodic leg movements during sleep in healthy subjects. Sleep Med 2013;14: 555-561.

33. Koo BB, Sillau S, Dean DA 2nd, Lutsey PL, Redline S. Periodic limb movements during sleep and prevalent hypertension in the multi-ethnic study of atherosclerosis. Hypertension 2015;65:70-77.

34. Lusardi P, Mugellini A, Preti P, Zoppi A, Derosa G, Fogari R. Effects of a restricted sleep regimen on ambulatory blood pressure monitoring in normotensive subjects. Am J Hypertens 1996;9:503-505.

35. Ogawa Y, Kanbayashi T, Saito Y, Takahashi Y, Kitajima T, Takahashi K, et al. Total sleep deprivation elevates blood pressure through arterial baroreflex resetting: a study with microneurographic technique. Sleep 2003;26:986-989.

36. Schilling C, Schredl M, Strobl P, Deuschle M. Restless legs syndrome: evidence for nocturnal hypothalamic-pituitary-adrenal system activation. Mov Disord 2010;25:1047-1052.

37. De Vito K, Li Y, Batool-Anwar S, Ning Y, Han J, Ga X. Prospective study of obesity, hypertension, high cholesterol, and risk of restless legs syndrome. Mov Disord 2014;29:1044-1052.

38. Budhiraja P, Budhiraja R, Goodwin JL, Allen RP, Newman AB, Koo $\mathrm{BB}$, et al. Incidence of restless legs syndrome and its correlates. J Clin Sleep Med 2012;8:119-124.

39. Juuti AK, Laara E, Rajala U, Laakso M, Harkonen P, Keinanen-Kiukaanniemi S, et al. Prevalence and associated factors of restless legs in a 57-year-old urban population in northern Finland. Acta Neurol
Scand 2010;122:63-69.

40. Zanigni S, Calandra-Buonaura G, Giannini G, Tonon C, Cortelli P, Provini F. The association between restless legs syndrome, cardiovascular and metabolic diseases: hypotheses and evidence from the literature. Arch Ital Biol 2015;153:170-183.

41. Innes KE, Selfe TK, Agarwal P. Restless legs syndrome and conditions associated with metabolic dysregulation, sympathoadrenal dysfunction, and cardiovascular disease risk: a systematic review. Sleep Med Rev 2012;16:309-339.

42. LeFevre ML; U.S. Preventive Services Task Force. Behavioral counseling to promote a healthful diet and physical activity for cardiovascular disease prevention in adults with cardiovascular risk factors: U.S. Preventive Services Task Force Recommendation Statement. Ann Intern Med 2014;161:587-593.

43. Mong JA, Baker FC, Mahoney MM, Paul KN, Schwartz MD, Semba K, et al. Sleep, rhythms, and the endocrine brain: influence of sex and gonadal hormones. J Neurosci 2011;31:16107-16116.

44. Trotti LM, Bliwise DL, Greer SA, Sigurdsson AP, Gudmundsdottir GB, Wessel T, et al. Correlates of PLMs variability over multiple nights and impact upon RLS diagnosis. Sleep Med 2009;10:668-671.

45. Gosselin N, Lanfranchi P, Michaud M, Fantini L, Carrier J, Lavigne G, et al. Age and gender effects on heart rate activation associated with periodic leg movements in patients with restless legs syndrome. Clin Neurophysiol 2003;114:2188-2195.

46. Bailey M, Silver R. Sex differences in circadian timing systems: implications for disease. Front Neuroendocrinol 2014;35:111-139.

47. Sterne JA, Sutton AJ, Ioannidis JP, Terrin N, Jones DR, Lau J, et al. Recommendations for examining and interpreting funnel plot asymmetry in meta-analyses of randomised controlled trials. BMJ 2011; 343:d4002. 